Reseach Article

\title{
Spinal Epidermoids - Rare Tumours Posing a Diagnostic Dilemma
}

\author{
Sanjay Kumar ${ }^{1, ~ *, ~ K r i s h a n ~ K u m a r ~ Y a d a v ², ~ S a u r a b h ~ K u m a r ~ V e r m a ~}{ }^{3}$ \\ ${ }^{1}$ Department of Neurosurgery, Command Hospital (Central Command), Lucknow, India \\ ${ }^{2}$ Department of Neurosurgery, Command Hospital (Air Force), Bengluru, India \\ ${ }^{3}$ Department of Neurosurgery, Army Hospital (Research \& Referral), New Delhi, India
}

\author{
Email address: \\ paraeagles@gmail.com (S. Kumar) \\ ${ }^{*}$ Corresponding author
}

\section{To cite this article:}

Sanjay Kumar, Krishan Kumar Yadav, Saurabh Kumar Verma. Spinal Epidermoids - Rare Tumours Posing a Diagnostic Dilemma. Clinical Neurology and Neuroscience. Vol. 2, No. 3, 2018, pp. 56-60. doi: 10.11648/j.cnn.20180203.12

Received: December 18, 2018; Accepted: January 3, 2019; Published: January 29, 2019

\begin{abstract}
Spinal epidermoids are rare tumors comprising less than 1\% of all intraspinal tumors. These tumors are usually found as intramedullary space occupying lesions (SOLs) in cervico-dorsal and as intradural SOLs in lumbo-sacral region. Thier origin has been advocated to be congenital or acquired. These tumors have been reported in patients of age group 03 yrs to 55 yrs in various case reports/small series in literature. The usual presentation is that of slowly progressive spastic paraparesis / quadriparesis with or without sphincter involvement as in IMSOLs / IDEMs lesions of the spinal cord. These tumors pose a diagnostic dillema due to there rarity. The diagnosis of these tumors may be delayed as they have similar symptoms and signs as in any other intradural spinal patholgy. The preoperative diagnosis can be made with reasonable certainity dedicated MRI sequences (diffusion weighted \& ADC) are carried out. Since these tumors are benign, an early diagnosis gives the patient a realtively good prognosis. We report two such unusual cases which came as diagnostic surprise on operative table and that too within a period of 06 months. Microscopic total excision relatively early in the course of the illness in both these patients had satisfactory outcome with good neurological recovery and no recurrence over last 24 months.
\end{abstract}

Keywords: Epidermoid Cyst, Intradural, IDEM, Spinal, Diffusion Weighted Images (DWI)

\section{Introduction}

Epidermoid cysts of the spine are relatively rare lesions, less than $0.5-1 \%$ of all spinal tumours $[1,2,3]$. These tumours are generally located in cervicodorsal region where they are intramedullary or in lumbosacral region where they are intradural extramedullary $[3,4,5]$. The genesis is usually congenital in former and iatrogenic in latter [6]. The genesis of congenital spinal epidermoids is an anomalous implantation of ectodermal cells during the closure of the neural tube between the third and fifth week of embryonic life $[1,7]$. The iatrogenic group usually have a history of lumbar puncture / spinal surgery / trauma. They are slow growing lesions and they generally present in the middle age with pain and features of any other intradural spinal lesion. The timely diagnosis of this tumour is important as early total excision of the tumour has very good long term prognosis $[1,2]$. Most series do not distinguish between subdural and intramedullary epidermoid cysts. Spinal subdural epidermoid cysts where total excision is possible and prognosis is better are rare and needs to be distinguished from intramedullary variants. We report two such cases coming as diagnostic surprise on operating table within a period of 06 months, diagnosed and operated within three years of onset of the clinical features. Both the patients are neurologically well preserved at 24 months follow up.

\section{Case Reports}

\subsection{Case 1}

A 40 years old lady presented with history of low back ache of 02 years duration associated with radicular pain in the region of L3-L5 dermatome of left lower limb. This pain was 
also associated with paraesthesia and thinning of the left lower limb with progressive weakness of the limb of 01 year duration. There was no history of meningitis, lumbar puncture, spinal surgery, trauma or sphincter involvement. Examination revealed wasting of left leg, flaccid monoparesis (MRC grade 4/5) left lower limb, deep tendon reflexes were sluggish in left lower limb, sensory loss over L3 - L5 dermatome with sacral sparing. No evidence of spinal dysraphism or spinal surgery was noted.

Contrast enhanced MRI scan revealed a well defined 30x15 $\mathrm{mm}$ intradural lesion at the level of L3 -L4 vertebral body which was isointense to cord on T1W images (Figures $1 \& 2$ ), hyperintense to cord on T2W images (Figures $3 \& 4$ ) and had no post contrast enhancement after gadolinium (Gd-DTPA) injection (Figure 5).

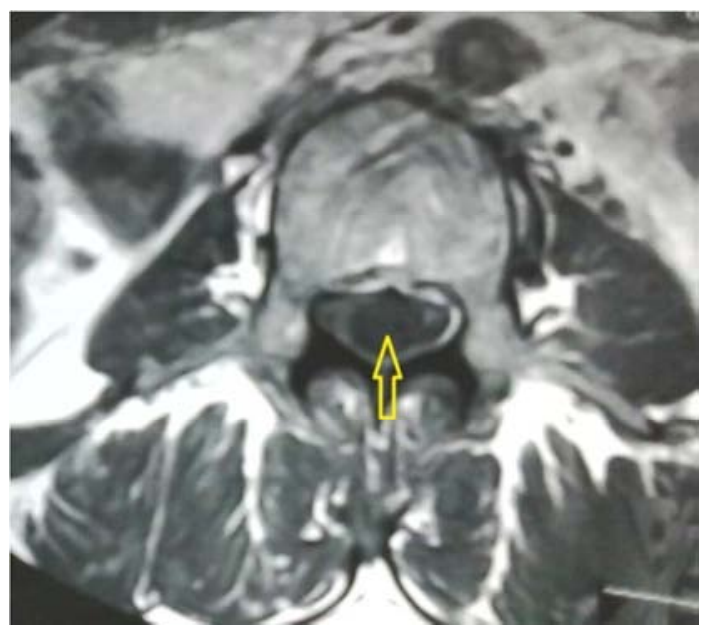

Figure 1. T1W axial section MRI showing intradural hypointense lesion.

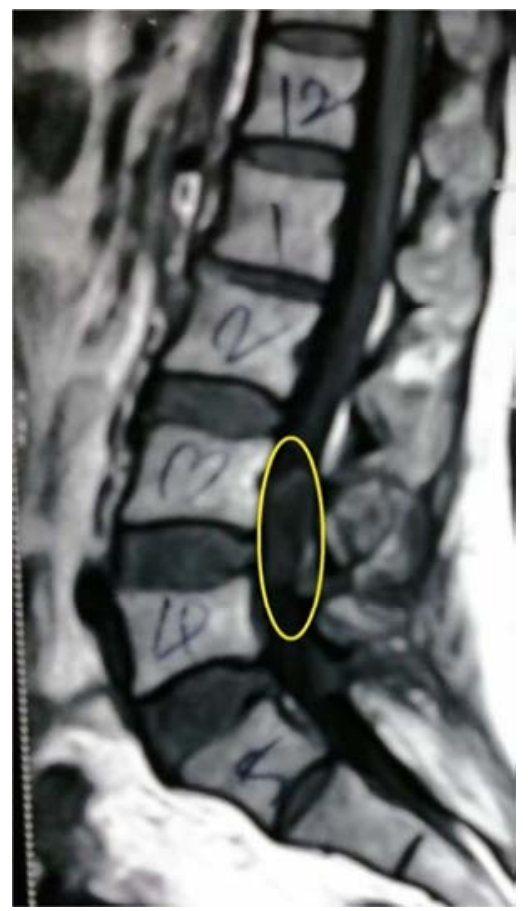

Figure 2. T1W saggital section MRI showing intradural hypointense lesion at the level of lumbar vertebrae $3 \& 4$.

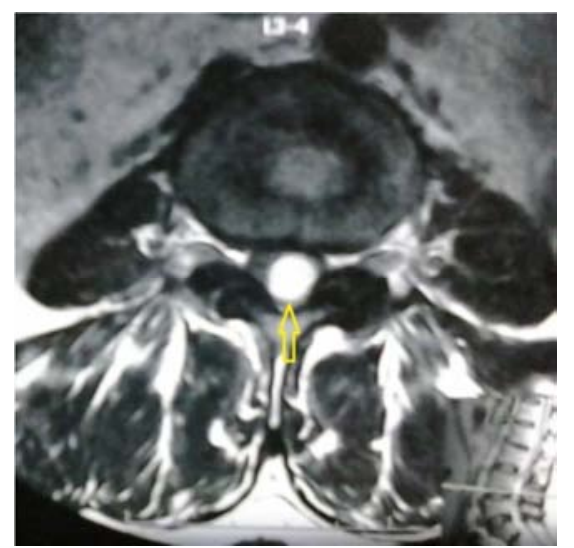

Figure 3. T2W axial section MRI showing intradural hyperintense lesion.

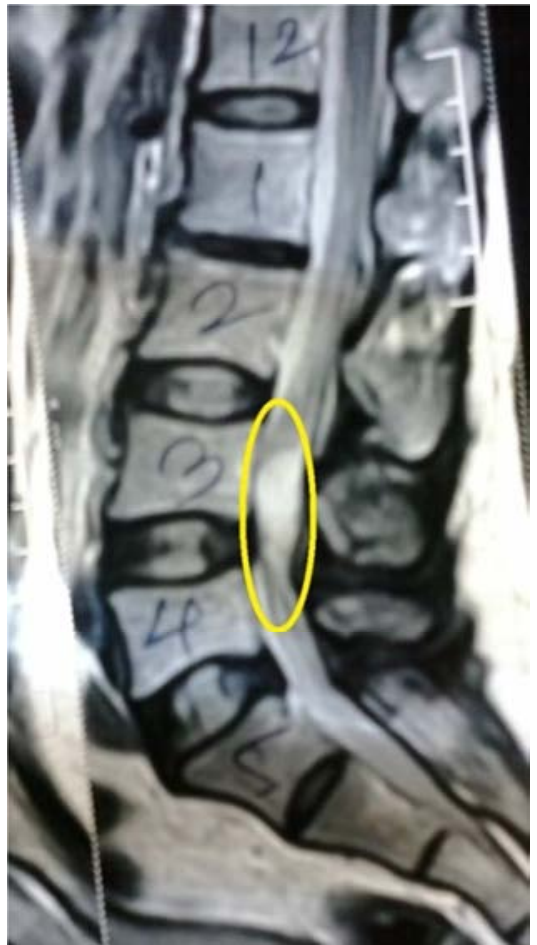

Figure 4. T2W saggital section MRI showing intradural hypointense lesion at the level of lumbar vertebrae $3 \& 4$.

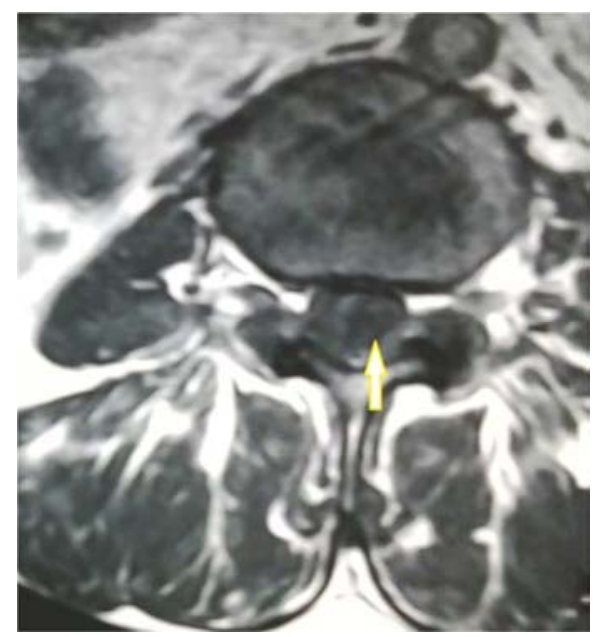

Figure 5. T1W post contrast axial section showing no contract enhancement of the lesion. 
There was no evidence of spinal dysraphism. The patient underwent laminectomy L3-L4 and total excision of the tumour. Intra-operatively a well defined pearly - white flaky mass (Figure 6) was found after the durotomy which was compressing and displacing / displaying the cauda equina postero-laterally.

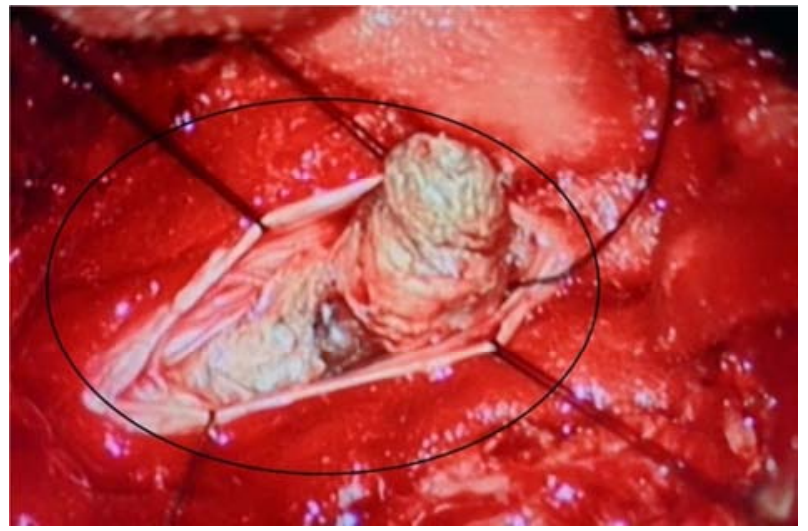

Figure 6. Intra-operative image showing the characteristic white flaky lesions depicting the epidermoid.

The capsule of the cyst was intimately attached with few of the nerve roots where it was left as its excision would have possibly worsened the patient's neurological deficits. Post operative recovery of the patient was uneventful and at two years follow-up patient has no evidence of recurrence or fresh neurological deficits.

\subsection{Case 2}

A 42 years old male presented with similar sign and symptoms which were of 03 years duration with involvement of the bladder. Again there was no history of meningitis, lumbar puncture, spinal surgery or trauma. MRI (Figures 7 12) had similar findings with an intradural non enhancing lesion at L3-L5 level. Patient underwent laminectomy L3-L5 and total excision of the tumour. Patient has had good post operative recovery with alleviation of his bladder symptoms and no recurrence / fresh neurological deficits at 21 months follow up period.

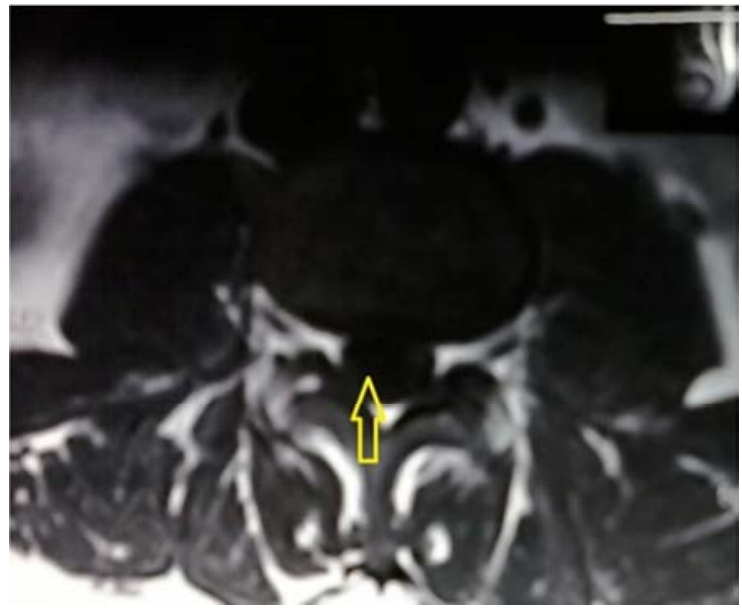

Figure 7. TIW axial section MRI showing intradural hypointense lesion.

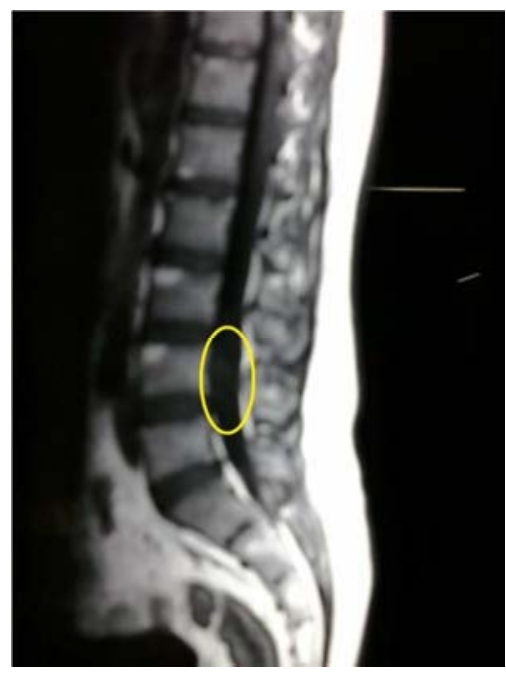

Figure 8. T1W saggital section MRI showing intradural hypointense lesion at the level of lumbar vertebrae $3 \& 4$

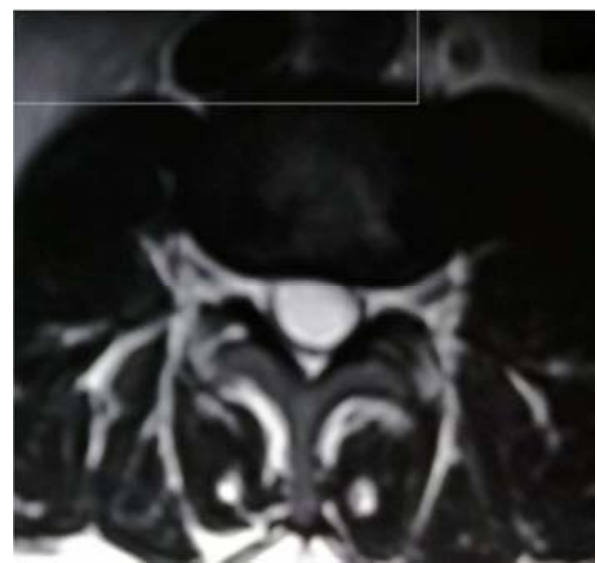

Figure 9. T2W axial section MRI showing intradural hyperintense lesion.

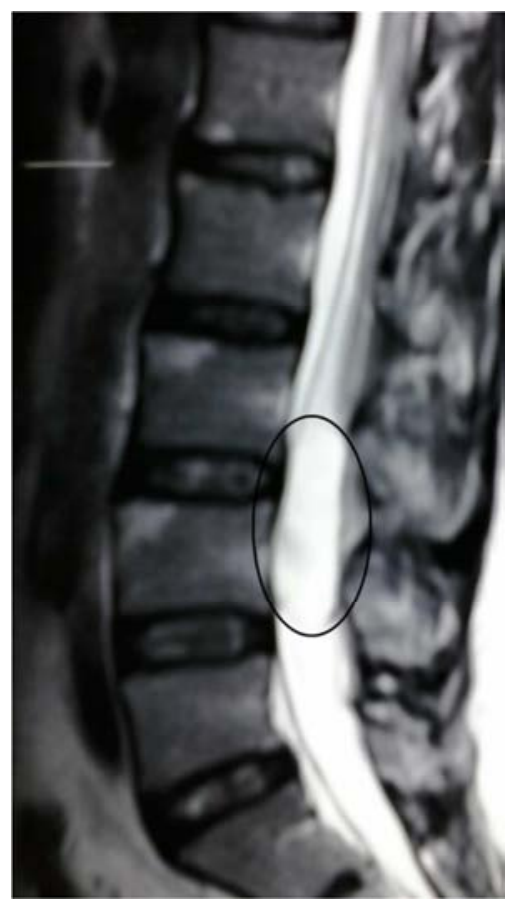

Figure 10. T2W saggital section MRI showing intradural hypointense lesion at the level of lumbar vertebrae. 


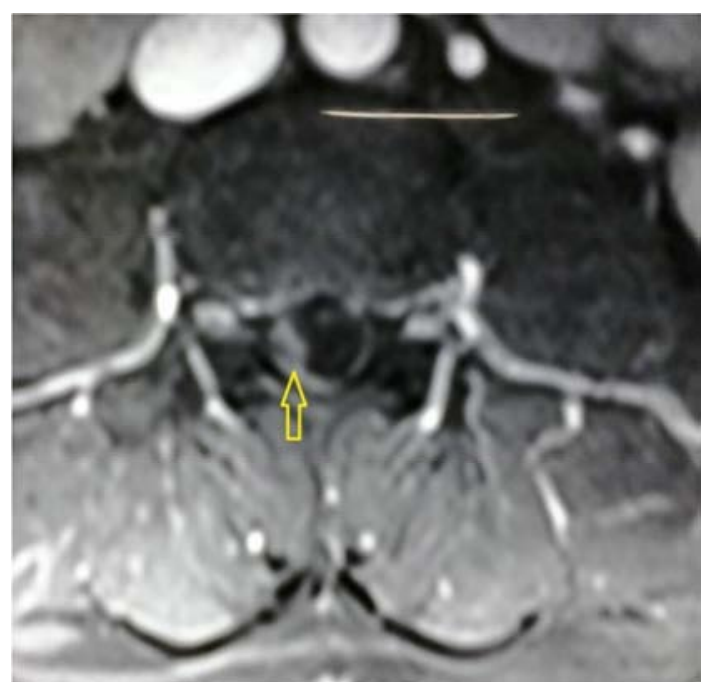

Figure 11. T1W post contrast axial section showing mild contrast enhancement of the capsule of the lesion.

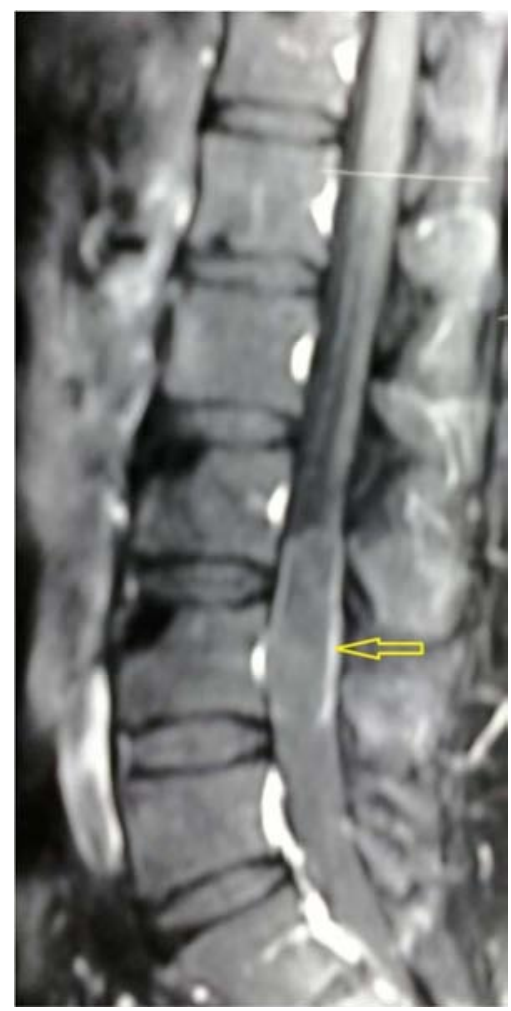

Figure 12. $T 1 W$ post contrast saggital section showing minimal contrast enhancement of the capsule of the lesion.

\section{Discussion}

The incidence of epidermoid cysts among intracranial tumours in most series is estimated to be $0.2-1 \%[1,2,8]$. It is much less among spinal tumours. Guidetti and Gagliardi [9] reported a series of 3894 intracranial and 452 intraspinal tumours in patients of all ages and found an incidence of $0.8 \%$ for cranial epidermoids and $0.7 \%$ for spinal epidermoid cysts. Intraspinal epidermoids may be congenital or acquired. Congenital epidermoids are believed to be caused by inclusion of ectoderm at the time of closure of the neural tube between the $3^{\text {rd }}$ and $4^{\text {th }}$ week of foetal life $[3,5,11]$. On the other hand acquired epidermoids are usually known to follow lumbar punctures, meningitis, dermal sinuses surgery and spinal surgeries/trauma. Manno et al [10] reported a series of 90 intraspinal epidermoid cysts collected from the literature, of which 39 were acquired and 51 congenital. According to Manno et al [10] spinal epidermoid tumours may be classified into five groups depending on whether the patients have: i) history of tuberculous meningitis, ii) history of lumbar puncture, iii) communicating dermal sinus, iv) history of trauma, v) or other disorders. These lesions are found commonly in the subdural, extramedullary space of the spine [1]. They may be associated with various spinal dysraphism such as dermal sinus, spina bifida, split cord malformations or enterogenous cysts [12].

Symptoms of spinal epidermoid cysts are directly related to tumour size and site and often arise for the first time in middle aged individual $[1,13]$ as was the case in our patients. These lesions remain asymptomatic for extended periods of time with various series reporting follow-up ranging from 2 to 10 years [13]. These benign masses present with pain and features of intradural space-occupying lesions which compress the medullary cone and the roots of the cauda equina. They have a slow growth process [2] lasting for many years. Their sign and symptoms are no different from any other spinal intradural lesion and present as progressive quadriparesis / paraperesis, sensory loss, urological manifestations and back/leg pain [4] (as was the case in our patients) hence there may be delay in the diagnosis.

The diagnostic modality of choice is contrast enhanced MRI of the spinal cord [14]. They are commonly hypo to isointense on T1-weighted and hyperintense on T2-weighted images. They do not usually enhance with contrast. However, the signal characteristics of epidermoid tumours are known to vary widely [15]. The apparent diffusion coefficient (ADC) values indicated restricted diffusion within the mass.The differentials of a spinal epidermoid cyst includes cystic schwannoma, meningioma, hemangioblastoma, arachnoid cysts, metastasis and so on. Pathologically, an epidermoid cyst contains keratin, cholesterol crystals, and desquamated epithelial cells [16]. If ruptured, the disseminated material of the cyst may produce a vigorous inflammatory reaction.

Most series do not distinguish between subdural and intramedullary epidermoid cysts. Spinal subdural epidermoid cysts where total excision is possible and prognosis is better are rare and needs to be distinguished from intramedullary variants [11]. In our series both the cases belonged to this intra/sub dural - extramedullary group.

Surgery is the treatment of choice for spinal epidermoids and maximal resection should be attempted [17]. However most authors do not advocate aggressive removal of the capsule as it is often intimately adherent to the spinal cord and neural structures (as we did in our two cases) and attempt to remove the wall in toto may carry a high risk of worsening of the neurological deficits $[11,18]$. The risk of recurrence exists. However, in most cases, even partial removal of the intramedullary epidermoid resulted in total remission of 
symptoms. If recurrence does occur, another surgery may relieve the symptoms again $[11,18]$.

\section{Conclusion}

Spinal epidermoid cysts are indeed rare tumours which are difficult to diagnose clinically. MRI of the spine with contrast and diffusion weighted images are the modality of choice for diagnosis. Microscopic gross total excision is the treatment of choice [19]. These tumours usually come as surprise on the operative table and hence continue to interest us all.

\section{References}

[1] Scarrow AM, Levy EI, Gerszten PC. Kulich SM. Chu CT. Welch WC. Epidermoid cyst of thoracic spine: case history. Clin Neurol Neurosurg 2001; 103 (4):220-2.

[2] Gonzalvo A, Hall N, McMahon JH, Fabinyi GC. Intramedullary spinal epidermoid cyst of the upper thoracic region. J Clin Neurosci; 200916 (1):142-4.

[3] Cataltepe O, Berker M, Akalan N. A giant intramedullary spinal epidermoid cyst of the cervicothoracic region. Pediatr Neurosurg 2004; 40 (3):120-3.

[4] Ferrara P, Costa S, Rigante D et al. Intramedullary epidermoid cyst presenting with abnormal urological manifestations. Spinal Cord 2003; 41 (11):645-8.

[5] Teksam M, Casey So, Michel E, Benson M, Truwit CL. Intraspinal epidermoid cyst.: diffusion - weighted MRI. Neuroradiology 2001; 43 (7)572-4.

[6] Maiuri F, Gangemi M, Cavallo LM, De Divitiis E. Dysembryogenetic spinal tumours in adults without dysraphism. Br J Neurosurg 2003; 17:234-8.

[7] Jeong IH, Lee JK, Moon KS, Kwak HJ, Joo SP, Kim TS. Iatrogenic intraspinal epidermoid tumour: Case report. Paediatric Neurosurgery 2006; 42:395-8.
[8] Penisson IB, Gilles G, Gandon Y: Intramedullary epidermoid cyst evaluated by computed tomographic scan and MRI. Case report. Neurosurgery 1989; 25: 955-959.

[9] Guidetti B, Gagliardi FM: Epidernoid and dermoid cysts clinical evaluation and late surgical results. L Neurosurg 1997; 47: 12-18.

[10] Manno NJ, Uihiein A, Kernohan JW: Intraspinal epidermoids. J Neurosurg 1962; 19: 754-765.

[11] Chandra PS, Manjari T, Devi PI, Chandramouli BA, Srikanth SG, Shankar SK. Intramedullary spinal epidermoid cyst. Neurol India 2000; 48; 75-7.

[12] Lee JH et al. Intramedullary epidermoid cyst in thoracolumbar region: A case report. Kor J Spine 2008; 5 (3): 219-224.

[13] Sun J, Zhang Q, Bao X. Diagnosis and surgical treatment of intradural epidermoid cyst of the spinal cord. Zhonghua Wai Ke Za Zhi 1998; 36:52-3.

[14] Jellema K, Overbeeke JJ, Teepen HL, Visser LH. Time to diagnosis of intraspinal tumours. Eur J Neurol 2005; 12 (8): 621-4.

[15] Er U, Yigitkanli K, Kazanci A, Bavbek M. Primary lumbar epidermoid tumour mimicking schwannoma. J Clin Neurosci $2006 ; 13: 130-3$.

[16] Carré S, Sanoussi S, Dietemann JL, Salatino S, Guessoum M. Intraspinal epidermoid cyst. J Neuroradiol 1997; 24:65-7.

[17] Yin et al.: Surgery and outcomes of six patients with intradural epidermoid cysts in the lumbar spine. World Journal of Surgical Oncology 2014 12:50

[18] Osborne D. R. Epidermoid and dermoid tumours: Radiology. In Neurosurgery; Vol I. Wilkins R. H. and Rengachary S. S. (Ed.). McGraw-Hill Book Company (USA).

[19] Vivek B. Beechar, Pascal O. Zinn, Kent A. Heck, Gregory N. Fuller, Inbo Han, Akash J. Patel, Alexander E. Ropper. Spinal Epidermoid Tumors: Case Report and Review of the Literature. Neurospine. 2018 Jun; 15 (2): 117-122. 